\title{
Analyzing the performance of the Major League Baseball Teams by using the Data Envelopment Analysis
}

\author{
Yanzhi Bi ${ }^{1}$
}

\begin{abstract}
Professional teams are commercial and recreational organizations, and team managers always set their goals to be playing well and benefitting more in a highly competitive environment. In order to measure the ability of the professional teams to make reasonable use of resources and create various outputs, this study employs the Data Envelopment Analysis (DEA) model to measure the efficiencies of 30 Major League Baseball (MLB) teams. The results showed that the inefficiencies were due to pure technical inefficiencies rather than scale effects, and the scale efficiency on average is more higher than the other efficiencies, applying the managers in the Major League Baseball Teams have higher ability of controlling the scale change.
\end{abstract}

Keywords: Major League Baseball, Data Envelopment Analysis, Technical efficiency, Pure technical efficiency, Scale efficiency.

${ }^{1}$ Zhejiang University of Finance and Economics.

Article Info: Received: May 6, 2021. Revised: May 27, 2021.

Published online: May 31, 2021. 


\section{Introduction}

An increasing number of researches pay much attention on the performance evaluation of professional sports teams. Nowadays, living in a rapidly changing environment and highly competitive society, it is important to analyze the gap between different organizations based on the input mix and outputs, which is crucial to maintain the competitiveness of organizations. Each professional team has its own specific mode of operation and the existence of professional sports teams is closely related to their performance. There are several major approaches can be used to measure the operational performance of sport teams (Scully, 1994; Smart and Wolfe, 2000). However, most of previous studies utilized a single index as input or output variable to estimate the performance of professional sports teams. For instance, Kahn applied the percent of awards as a special indicator to evaluate performance of professional sports teams. This study found that if a sports team higher percent of awards than other teams, the team's performance is better. Additionally, Scully (1994) used the ratio of team score to opponent's score as a part of inputs to calculate the operational performance of professional sports teams. In order to measure operational efficiency and performance of professional sports teams in a more comprehensive prospective, an analysis of performance that considers multiple inputs and outputs is required.

Since the first introduction of Data Envelopment Analysis (DEA) in the late 1970s, this method has been wildly employed to estimate the efficiency or performance of a decision making unit (DMU) on the basis of input and output mix. (Charnes, Cooper and Rhodes, 1978) DEA is linear programming model that shows a means to build a benchmark DMU for researchers, which can identify and divide up the efficiency and inefficient DMUs and provide recommendations for the further development and improvement. Compared with other approaches, DEA is the main method to analyze the efficiency and performance of professional sports teams (Lewis and Sexton, 2004; Cooper et al., 2009; Barros and Leach, 2006; Hung and Wang, 2012). According to the previous literature mentioned above, DEA can be applied to evaluate operational performance effectively. Hence, in this study, we construct a DEA model as the main methodology to estimate the operational performance of professional sports teams in Major League Baseball (MLB) and provide related suggestions of future promotion for the managers in professional sports teams.

MLB is an American professional Baseball organization that is one of the four Major North American professional sports leagues. It is divided into the American League (AL) and the National League (NL) and has operated as separate legal entities since 1901 and 1876, respectively. In 2000, the league merged into one organization, the Baseball League. MLB is responsible for minor league baseball, with about 240 teams participating in major league clubs. MLB works with the International Baseball Federation, which also manages the international World Baseball Classic. Today, there are 30 teams in MLB: 29 in the United States and one in Canada. The performance of a professional sports teams is highly related to 
its further sustainability over the next few years. Performance is the ratio of output to standards set within the organization (Kearney, 1984; Hung, He and Lu, 2014). It can be viewed as a measure of how well an organization achieves its goals. The measurement of performance is an analysis utilized to access operational efficiency (Mentzer and Konarad, 1991; Chang, Tsai and Hung, 2013). Professional sports teams should effectively calculate resource utilization and estimate their operational performance by implementing tasks that generate the highest benefit with limited resources (Tsai and Hung, 2014). Measurements of performance in professional sports teams when compared to those in other industries and can usually be obtained from published data (Duchon and Jago, 1981). The operation of professional sports teams can be regarded as a production process that turns players' performance into victory. Consequently, in order to evaluate the operational performance of professional sports teams, the players' performances, such as the scores of players and the gained bases, are used as the input variables, and the number of wins is adopted as the out variable. Rotternberg (2015) regarded the operation of professional sports teams as a production process, in which teams invest in talented coaches, players and venues, and then converts them into the outputs of teams, which is the final income gained.

Currently, a great number of literatures that estimated baseball performance in DEA method have been presented (Howard and Miller, 1993; Bloom, 1999; Sexton and Lewis, 2003; Lewis et al., 2007; Jane et al., 2010; Volz, 2016). Howard and Miller (1993) applied a DEA approach to calculate the pay equity of professional sports teams in MLB and measure players' performance to determine whether they deserve their current salary. They found that nearly 48 percent of professional players were underpaid, and these players needed a pay increase of 23 percent. Bloom (1999) analyzed the performance of MLB teams and professional players from 1985 to 1993 , and he found that a larger salary distribution had a positive effect on the performance of high-wage players and a negative effect on the performance of lowwage players. Excessive pay differences exert a negative impact on the performance of whole team. Sexton and Lewis used two-stage DEA model to access the efficiency value of professional sports teams in MLB. The first stage was utilized to measure whether the wage input was suitable to the performances of players. At this stage, the player's total salary was the input variable, and the total base obtained and the total base given up were viewed as the output variables. The second stage was "games on the field", which measures whether a player's performance convert into wins in the regular season. The output variables in the first stage were taken as the input factors of the second stage, and the number of victories was viewed as the output variable in the second stage. The estimated results presented 2 teams showed improvement in the front office stage and 5 teams showed promotion in the field stage.

Lewis et al. (2007) employed the same framework as Sexton and Lewis (2003) to figure out the most competitive minimum wage. They found that this wage rose from 6.19 million dollars to 38.67 million dollars, with an average annual increase of 10.7 percent. Jane et al. (2010) utilized the stochastic frontier model to access the 
individual efficiency of professional baseball players and analyze the correlation between efficiency and club performance. Their study found that winning percentage was related to runs scored, safe hits and home runs, rather than bases on balls and stolen bases. They concluded that winning had the highest correlation with scoring, and that players would strive for scoring opportunities to earn higher wage in the future. Volz (2016) presented a DEA model to estimate the output oriented efficiency of manager in MLB professional sports teams from 1986 to 2011.

In terms of the findings from previous studies, most scholars applied input or output oriented DEA model and without considering the condition of non-oriented. Therefore, in this study, we construct a non-oriented DEA model to evaluate the performance efficiency of 30 professional sports teams in MLB in order to promote the accuracy of efficiency measurement, which can provide reference for the managers in each team. The rest of this paper is organized as follows: Section 2 shows the methodology of DEA model; Section 3 shows estimated results, and Section 4 offers several conclusions of this study.

\section{Methodology}

DEA is an assessment procedure that does not require pre-settlement of the weighting factor and is designed to determine the efficiency of the various decisionmaking units (DMU) by calculating the ratio between multiple inputs and multiple outputs (Charnes, Cooper, and Rhodes, 1978; Hansen, 2002). DEA efficiency analysis has been widely used in various fields, such as banking (Gelade and Gilbert, 2003), hospitals (Dervaux et al., 2004), publication (McWilliams et al., 2005), NPD project execution efficiency (Swink, Talluri, and Pandejpong, 2006), etc. Its application in sports is also very extensive. Cooper et al. (2009) and Fizel and D'ltri (1997) conducted a DEA to measure the performance of players in the National Basketball Association (NBA) and the National Collegiate Athletic Association (NCAA), respectively. Barros and Leach (2006) also employed the DEA method to measure the efficiency of football teams in the English Premier League Clubs, while Sexton and Lewis (2003) adopted a two-stage DEA model to analyze the efficiency of each team in the MLB.

In this study, following the method proposed by Charnes, Cooper and Rhodes (CCR) model, we construct the DEA method to access the performance efficiency of DMUs, which is presented as follows:

s.t.

$$
\operatorname{Max} \sum_{\mathrm{i}=1}^{\mathrm{M}} \mathrm{u}_{\mathrm{i}} \mathrm{y}_{\mathrm{i} 0} / \sum_{\mathrm{i}=1}^{\mathrm{M}} \mathrm{v}_{\mathrm{i}} \mathrm{x}_{\mathrm{i} 0}
$$

$$
\begin{gathered}
\frac{\sum_{\mathrm{i}=1}^{\mathrm{M}} \mathrm{u}_{\mathrm{i}} \mathrm{y}_{\mathrm{il}}}{\sum_{\mathrm{i}=1}^{\mathrm{M}} \mathrm{v}_{\mathrm{i}} \mathrm{x}_{\mathrm{il}}} \leq 1 \quad \forall \mathrm{l}=1 \\
\mathrm{u}_{\mathrm{i}}, \mathrm{v}_{\mathrm{j}} \geq 0, \forall \mathrm{i}=1 ; \forall \mathrm{j}=1
\end{gathered}
$$


The purpose of Equations (1) is to find and maximize the ratio of outputs to inputs, where $\mathrm{K}$ represents the number of $\mathrm{DMU}$, and $\mathrm{M}$ and $\mathrm{N}$ are the number of outputs and inputs owned by the each DMU, respectively. $v_{j}$ and $u_{i}$ represent the weights of the jth input and ith output. $y_{i 1}$ and $x_{i 1}$ represent the number of jth input and ith output. Since DEA model is used to study the production frontier to estimate the efficiency of a special DMU, the effective teams are those that operate at the frontier. Teams that operate below the frontier are considered technically inefficient DMUs. In addition to the CCR model, this study also measured the operating efficiency using the Banker Charnes Cooper (BCC) model (Banker, Chames, and Cooper, 1984). The biggest difference between these two models lies in that the former cannot identify whether an inefficient DMU is caused by inefficient technology or an inefficient scale, while the BCC model can provide pure technical efficiency, scale efficiency, and returns to scale of the DMU. The technical efficiency (TE) of a DMU refers to the conversion of inputs into outputs relative to the best practice. In other words, TE is the ability to minimize the use of inputs in given outputs or to obtain the maximum output from given inputs. The pure technical efficiency (PTE) is a measure of technical efficiency without scale efficiency and reflects the managerial performance. The scale efficiency (SE) is defined by the ratio of a TE score to a PTE score and it is a measurement which can be regarded as a criterion to choose the optimum size or scale. If a team is scale efficient, the ratio is equal to one; otherwise, if the ratio is less than one, then the team is scale inefficient. Inappropriate scale is a cause of scale inefficiency and scale inefficiency can be divided into two forms: decreasing returns to scale (DRS) and increasing returns to scale (IRS). Decreasing returns to scale implies that a team is too large and increasing returns to scale implies that a team is too small.

In this study, following the method proposed by Charnes, Cooper and Rhodes (CCR) model, we construct the DEA method to access the performance efficiency of DMUs, which is presented as follows:

s.t.

$$
\operatorname{Max} \sum_{\mathrm{i}=1}^{\mathrm{M}} \mathrm{u}_{\mathrm{i}} \mathrm{y}_{\mathrm{i} 0}-u_{0} / \sum_{\mathrm{i}=1}^{\mathrm{M}} \mathrm{v}_{\mathrm{i}} \mathrm{x}_{\mathrm{i} 0}
$$

$$
\begin{array}{r}
\frac{\sum_{\mathrm{i}=1}^{\mathrm{M}} \mathrm{u}_{\mathrm{i}} \mathrm{y}_{\mathrm{il}}-u_{0}}{\sum_{\mathrm{i}=1}^{\mathrm{M}} \mathrm{v}_{\mathrm{i}} \mathrm{x}_{\mathrm{il}}} \leq 1 \quad \forall \mathrm{l}=1, \mathrm{~K}, \mathrm{M} \\
\mathrm{u}_{\mathrm{i}}, \mathrm{v}_{\mathrm{j}} \geq 0, \forall \mathrm{i}=1, \mathrm{k}, \mathrm{M} ; \forall \mathrm{j}=1, \mathrm{~K}, \mathrm{M}
\end{array}
$$

Where $u_{0}$ is the intercept of the production function. If $u_{0}$ is positive, the line section of corresponding production frontier belongs to the DRS; If $u_{0}$ is negative, the line section of corresponding production frontier belongs to the IRS If $u_{0}$ is zero, the line section of corresponding production frontier belongs to the Constant Returns to Scale (CRS). 


\section{Empirical results}

\subsection{Data}

In order to measure the business performance of professional sports teams, this study takes MLB as the research object and measures the business performance of each team. The MLB is the world's top professional baseball league, consisting of 30 teams. Each team plays 162 games in the regular season, and only one team can win the World Series, which is pretty competitive. Unlike amateur baseball, MLB is considered a profit-oriented business, constantly in need of new information to help managers win games and turn a profit. Accurate measurement of operating performance is critical and useful. For efficiency analysis of DEA, this study uses a model with two input variables (centrality and total salary) and three output variables (wins, present value and team benefits) to calculate the measured values. The main sources of the data information in this study come from USA Today, Forbes.com, and official MLB data. We present the statistics of the variables in Table 1.

The average total salary bill for each team was $\$ 82,633,066$, of which the highest was the New York Yankees with a total payroll of $\$ 189,639,045$. The average current value reached $\$ 471.63$ million; the lowest and the highest were $\$ 256$ million and $\$ 1,306$ million, respectively. The average revenues for each team were $\$ 182.96$ million.

Table 1: Descriptive data for input and output variables

\begin{tabular}{|c|c|c|c|c|}
\hline Variables & Mean & SD & Maximum & Minimum \\
\hline Salary & $82,633,066$ & $33,352,233.37$ & $189,639,045$ & $24,123,500$ \\
\hline $\begin{array}{c}\text { Current Value } \\
\text { (\$ million) }\end{array}$ & 471.63 & 208.07 & 1,306 & 256 \\
\hline Revenues (\$ million) & 182.96 & 40.52 & 327 & 128 \\
\hline Wins & 81.03 & 9.13 & 96 & 66 \\
\hline
\end{tabular}

\subsection{The performance analysis of MLB}

To clearly illustrate the operational efficiency of each team in MLB, this study conducted respective analyses of technical efficiency, pure technical efficiency, scale efficiency, returns to scale, and efficiency reference collection. The efficient DMUs are ranked according to the score of technical efficiency. If the technical efficiency score of a team is equal to 1 , the team is considered as a reference benchmark for the inefficient teams. The results in Tables 2-4 showed that the average technical efficiency, pure technical efficiency, and returns to scale of each team in the MLB were $0.875,0.91$, and 0.96 , respectively. The technical efficiency of each team in the MLB still had an improvement margin of $12.5 \%$, and the inefficiency of the technique results from purely technical inefficiencies rather than scale inefficiencies. If team managers want to enhance their comprehensive technical efficiency, their first priority should be to improve pure technical 
efficiencies, followed by scale efficiencies. Taking the Baltimore Orioles as an example, its pure technical efficiencies and scale efficiencies are both inefficient. The major cause for these inefficiencies comes from the pure technical inefficiencies, indicating that the managers of the Baltimore Orioles should first enhance the efficiency of the input factor to improve the team scale.

Table 2: Efficiency values and their ranking of MLB teams

\begin{tabular}{|c|c|c|c|c|c|c|}
\hline Ref. & Team & TE & PTE & SE & Reference set & RTS \\
\hline 1 & $\begin{array}{c}\text { Arizona } \\
\text { Diamondbacks }\end{array}$ & 1.000 & 1.000 & 1.000 & $(1)$ & CRS \\
\hline 6 & Chicago White Sox & 1.000 & 1.000 & 1.000 & $(6)$ & CRS \\
\hline 8 & Cleveland Indians & 1.000 & 1.000 & 1.000 & $(8)$ & CRS \\
\hline 14 & Los Angeles Angels & 1.000 & 1.000 & 1.000 & $(14)$ & CRS \\
\hline 19 & New York Yankees & 1.000 & 1.000 & 1.000 & $(19)$ & CRS \\
\hline 27 & Tampa Bay Devil Rays & 1.000 & 1.000 & 1.000 & $(27)$ & CRS \\
\hline 30 & Washington Nationals & 1.000 & 1.000 & 1.000 & $(30)$ & CRS \\
\hline
\end{tabular}

The estimation of technical efficiency is the assumed results of constant returns to scale. As shown in Tables 2-4, of the 30 MLB teams, there were seven teams whose values for overall efficiency reached 1 and the remaining 23 teams were relatively inefficient, of which the minimum was 0.677. The teams with a technical score of 1 can be identified as the "best practice" teams, whereas the technical inefficiency for the remaining teams is calculated on the Euclidian distance from the frontier (Coelli, Prasada, and Battese, 2005). In order to reach the technical efficiency, input-output ratio adjustment for the inefficient teams is necessary.

Every year, the champions of the American League and National League participate in the World Series, and it is the major baseball event in North America. To obtain a spot in the World Series, teams with better records enter the playoffs to get the chance to compete for the World Series trophy. There are only eight places in the competitive playoffs and this study considered four efficient teams who were admitted into the division series or the league championship series in 2007; namely: Arizona Diamondbacks, Cleveland Indians, Los Angeles Angels, and New York Yankees. In other words, efficient teams properly utilize their resources and demonstrate their strengths in competition. Although the value of efficiency of the Boston Red Sox was only 0.963, below the efficient frontier, its efficiency is still higher than the other inefficient teams. Furthermore, this team won the 2007 World Series Trophy. The Kansas City Royals, with the lowest efficiency of 0.677, had a winning rate of only 0.426 . In other words, the efficiency value was mirrored in its performance and competition to some extent.

Pure technical efficiency is the calculated result under the BCC Model, which measures the efficiency of the input factor. As shown in Tables 2-4, of the 30 MLB teams, there were nine teams whose overall efficiency values reached 1 . Additionally, 21 teams were relatively inefficient, of which the minimum was 0.727 , 
indicating that these 21 teams failed to properly make use of their resources invested, and there was a large margin for improvements in pure technical efficiency. For example, the pure technical efficiency of the Cincinnati Reds, Milwaukee Brewers, and the Baltimore Orioles were all lower than 0.75 , indicating that they have not properly utilized the invested resources even though their scale efficiencies were all higher than 0.95 , making them ranked at the bottom of the technical efficiency rankings. This study suggests that the utilization of these three teams' resources should be reviewed to enhance their performance.

Table 3: Efficiency values and their ranking of MLB teams

\begin{tabular}{|c|c|c|c|c|c|c|}
\hline Ref. & Team & TE & PTE & SE & Reference set & RTS \\
\hline 2 & Atlanta Braves & 0.918 & 0.922 & 0.996 & $(6)(8)(19)$ & DRS \\
\hline 4 & Boston Red Sox & 0.963 & 1 & 0.963 & $(6)(8)(19)$ & DRS \\
\hline 5 & Chicago Cubs & 0.882 & 0.909 & 0.97 & $(8)(19)(27)$ & DRS \\
\hline 9 & Colorado Rockies & 0.844 & 0.977 & 0.863 & $(1)(27)$ & DRS \\
\hline 11 & Florida Marlins & 0.925 & 0.981 & 0.943 & $(1)(27)$ & DRS \\
\hline 12 & Houston Astros & 0.941 & 0.943 & 0.998 & $(6)(8)(19)$ & DRS \\
\hline 15 & Los Angeles Dodgers & 0.837 & 0.916 & 0.914 & $(8)(19)(27)$ & DRS \\
\hline 18 & New York Mets & 0.863 & 0.961 & 0.897 & $(19)(27)(30)$ & DRS \\
\hline 21 & Philadelphia Phillies & 0.815 & 0.815 & 0.999 & $(6)(8)(19)$ & DRS \\
\hline 23 & San Diego Padres & 0.858 & 0.892 & 0.961 & $(1)(8)(27)$ & DRS \\
\hline 24 & San Francisco Giants & 0.886 & 0.888 & 0.997 & $(6)(8)(19)$ & DRS \\
\hline 25 & Seattle Mariners & 0.798 & 0.799 & 0.997 & $(6)(8)(19)$ & DRS \\
\hline 26 & St. Louis Cardinals & 0.791 & 0.809 & 0.97 & $(6)(8)(19)$ & DRS \\
\hline
\end{tabular}

In addition to measuring pure technical efficiency, the BCC Model can also be used to calculate the scale efficiency value of each team. If the value of scale efficiency is 1 , the size of the team is currently appropriate; if the value is less than 1, the ratio between the input and the output is inappropriate. Inappropriate scale implies that a team is either too large or too small and the team needs to decrease or increase the team size. Thus, adjusting the input of team is a way to reaching the scale efficient (e.g., increasing the number of employees, size of coach team, etc.). In this study, there were seven teams operating with scale efficiency, while there were 23 teams whose scale efficiencies were less than 1 , indicating that these teams should adjust their scales to reach the optimal scale of production. Taking the Oakland Athletics and the Colorado Rockies as examples, their low technical efficiency values were due to their too low scale efficiency. If the Oakland Athletics expand their scale and the Colorado Rockies downsize their scale (decrease the number of employees, size of coach team, etc.), their technical efficiency will improve. 
Table 4: Efficiency values and their ranking of MLB teams

\begin{tabular}{|c|c|c|c|c|c|c|}
\hline Ref. & Team & TE & PTE & SE & Reference set & RTS \\
\hline 3 & Baltimore Orioles & 0.705 & 0.742 & 0.95 & $(6)(8)(19)$ & IRS \\
\hline 7 & Cincinnati Reds & 0.715 & 0.727 & 0.983 & $(8)(27)$ & IRS \\
\hline 10 & Detroit Tigers & 0.94 & 0.967 & 0.972 & $(8)(14)$ & IRS \\
\hline 13 & Kansas City Royals & 0.677 & 0.827 & 0.813 & $(6)(8)$ & IRS \\
\hline 16 & Milwaukee Brewers & 0.703 & 0.735 & 0.914 & $(1)(8)(27)$ & IRS \\
\hline 17 & Minnesota Twins & 0.811 & 0.906 & 0.894 & $(8)(14)$ & IRS \\
\hline 20 & Oakland Athletics & 0.83 & 0.929 & 0.893 & $(6)(8)(14)$ & IRS \\
\hline 22 & Pittsburgh Pirates & 0.952 & 1 & 0.952 & $(8)(27)$ & IRS \\
\hline 28 & Texas Rangers & 0.805 & 0.808 & 0.995 & $(8)(19)(27)$ & IRS \\
\hline 29 & Toronto Blue Jays & 0.791 & 0.852 & 0.928 & $(8)(14)$ & IRS \\
\hline
\end{tabular}

The necessary ratio adjustment between input and output can be determined by the returns to scale of the teams. As shown in Table 2-4, there were seven teams who reached a constant returns to scale (CRS), indicating that these teams were in an optimal state and no scale adjustment was needed. Of the 30 teams, however, there were 13 teams that operated in decreasing returns to scale (DRS), showing that the increasing volume of output in these teams was lower than that of the input and that these teams should be downsized. Taking the Boston Red Sox as an example, the pure technical efficiency was efficient while the scale efficiency was inefficient, which indicates that the present scale of the Boston Red Sox team is inefficient. Furthermore, there were 10 teams who had increasing returns to scale (IRS), indicating that these teams should expand their scale to become efficient. Taking the Oakland Athletics as an example, the major reason for the low technical efficiency comes from scale inefficiency. This team had a marginal IRS and should expand its scale to improve its efficiency.

Reference set is a benchmark which can provide the inefficient team with information for improving their efficiency and adjusting their input or output. Table 2-4 also lists the reference set for each team to improve their operational efficiency. Taking the Atlanta Braves as an example, its reference set are the Chicago White Sox, Cleveland Indians, and New York Yankees. In order to become an efficient team, the Atlanta Braves needs to reduce its input, such as salary expenditure (from 87.29 to 80.20 millions). The more often a team is used as a benchmark for reference, the stronger the robustness of the relative efficiency of this team is. The study found that the number of times the Cleveland Indians were used as a reference was 20, followed by the New York Yankees and Chicago White Sox, with numbers of 12 and 10 , respectively.

\subsection{The Boston matrix analysis}

In order to obtain an enhance picture of MLB' performance, the relation between the technical and scale efficiencies, the joint use of the technical efficiency and scale efficiency can highlight the potential performance improvements that management 
might be able to exploit, leading to better performance. Also, know what characters the baseball teams with high technical and scale efficiency have. This analysis is based on the scale-technical efficiency matrix as similar as Camanho and Dyson (1999) and shows in Figure 1.

The baseball teams located in the zone A at Figure1 have higher technical and scale efficiencies. They have good ability to manage their inputs and maximize outputs. It indicates that these teams have a diversification operation which is an important stratagem to improve enterprise benefit and management security. The higher this ratio, the more efficient the process of financial intermediation provided by the team. The zone D at Figure 1 represents the teams that have high technical efficiency and low scale efficiency. They are inefficient to create the profits but are efficient to manage their technology. For these teams, it is suggested to improve their profit based on this technical level. The zone $\mathrm{C}$ of Figurel represents the teams that are inefficient in term of technical and scale efficiency, these teams should rethink their strategies to improve the use of their resources. In these teams, they have a small team size, but their ratios of loans to deposits are highest. It stands for these teams focus on their traditional business, and ignores their assets management. It also shows that these teams have a lower manage level. A business cannot thrive without good management. Therefore, these teams should reorganize the resource and the working flow; strengthen efficiency management, to accommodate change of environment. The teams located in zone B of Figure 1 that have high scale efficiency and low technical efficiency, they are efficient to create profits but inefficient to manage their technology. Similarly, these teams have a relative high ratio for the loan to investment; it provides more profit increasing points than the teams in the zone II and III. It also can be explained that although these teams are similar to the teams in zone III, they prefer their investment to push or pull their profit margin trends to some extent. 


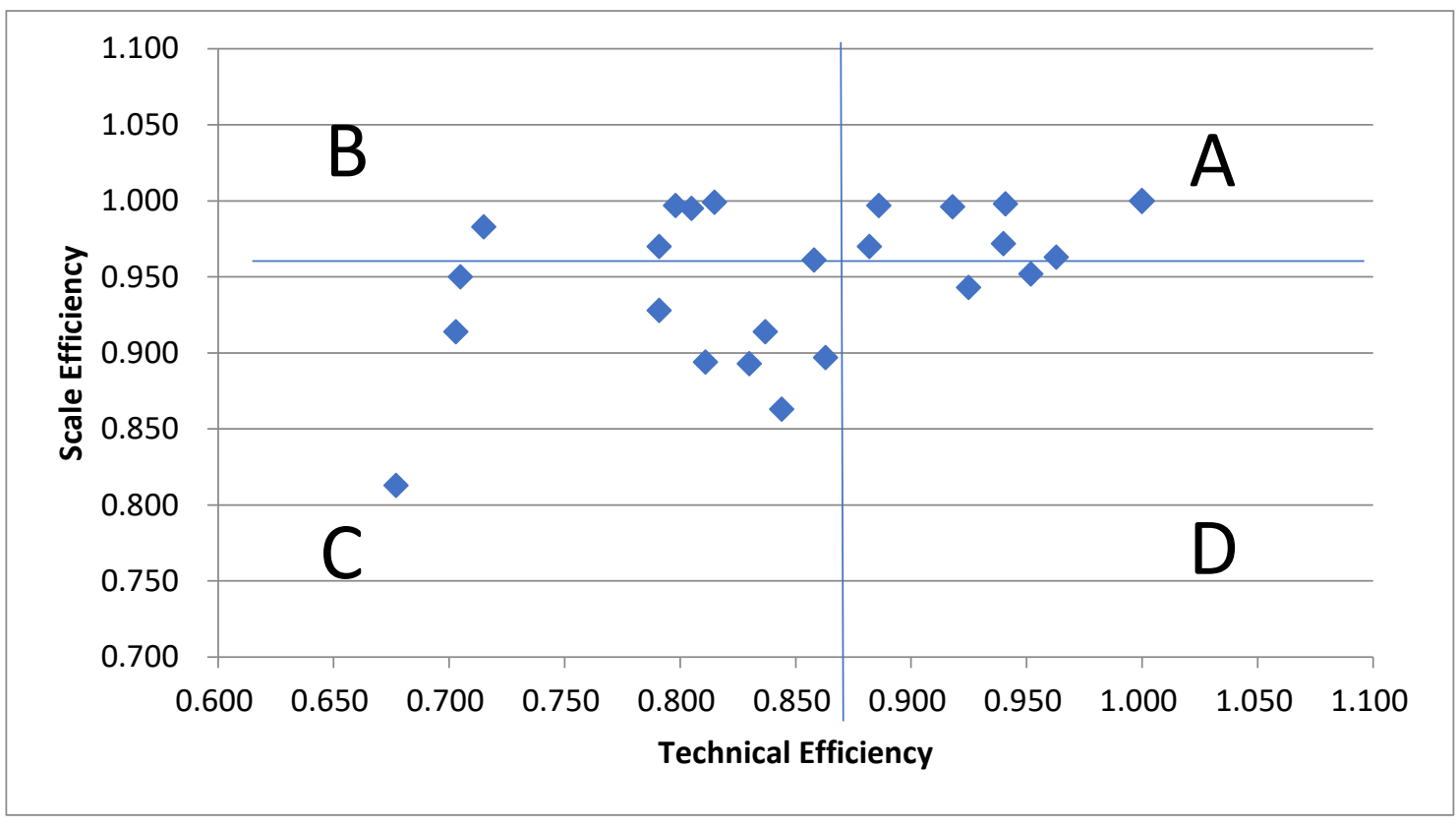

Figure 1: the Boston matrix analysis in the performance of MLB

\section{Conclusion}

Professional teams are commercial and recreational organizations, and team managers always set their goals to be playing well and benefitting more in a highly competitive environment. In order to measure the ability of the professional teams to make reasonable use of resources and create various outputs, this report analyzed the characteristics of multiple inputs and outputs through a DEA in order to measure the efficiency and performance of the 30 teams across two leagues of MLB.

This study makes a contribution from two aspects. First, when new teams can possess this subtle information, it would be helpful for these new teams to gather such information in order to formulate relative strategies. Since tacit knowledge is difficult to attain and collect, it is beneficial for players to study and grow in teams, especially if teams can interact with experienced players over the long term. Therefore, it was advised in this study that relative sports teams should not only employ rising star players and star players in this field, but also pay attention to recruiting experienced players who have played for many teams. Through the experienced players, teams can not only harvest extra information, but also form a stable force in order to enhance their performance. Secondly, this study is one of few studies on the influence of social networks on DEA performance measurement, and is also the first study to reflect the combination of sports performance measurement. In past studies on DEA performance measurement, most have made an analysis of observable and recordable data but rarely put forward or made quantitative researches of hidden and less visible phenomenon. Because the social network index can materialize hidden information, this report applied the social 
network index as the input item of performance measurement, which helps to increase its availability in DEA studies. This can be taken further in sports performance studies and used as a new perspective for exploring the origins of sports team performance.

Finally, although this report has made a deep analysis of MLB team performance, there still exists many phenomena that are related to the network but which are not conducted in this study. Hence, it is advised that further studies can make an analysis of relative social network indices, such as the centralization index, in order to compensate for the long-term omission of network relations in sports performance studies.

\section{References}

[1] Barros, C.P. and Leach, S. (2006). Performance evaluation of the English Premier Football League with data envelopment analysis. Appl Econ, 38(12), 1449-1458.

[2] Bloom, M. (1999). The performance effects of pay dispersion on individuals and organizations. Acad Manage J, 42(1), 25-40.

[3] Chang, C.C., Tsai, J.M. and Hung, S.W. (2013). Resolving the innovation puzzle of latecomers: the case of Taiwan. Technol Anal Strateg Manage, 25(4), 459-472.

[4] Charnes, A., Cooper, W.W. and Rhodes, E. (1978). Measuring the efficiency of decision making units. Eur J Oper Res, 2(6), 429-444.

[5] Cooper, W.W., Ruiz, J.L. and Sirvent, I. (2009). Selecting non-zero weights to evaluate effectiveness of basketball players with DEA. Eur J Oper Res, 195(2), 563-574.

[6] Dervaux, B., Ferrier, G.D., Leleu, H. and Valdmanis, V. (2004). Comparing French and US hospital technologies: a directional input distance function approach. Appl Econ, 36(10), 1065-1081.

[7] Duchon, D. and Jago, A.G. (1981). Equity and the performance of major league baseball players: An extension of Lord and Hohenfeld. J Appl Psychol, 66(6), 728-733.

[8] Gelade, G. and Gilbert, P. (2003). Work climate and organizational effectiveness: The application of data envelopment analysis in organizational research. Organ Res Methods, 6(4), 482-501.

[9] Hansen, M.T. (2002). Knowledge networks: Explaining effective knowledge sharing in multiunit companies. Organ Sci, 13(3), 232-248.

[10] Howard, L.W. and Miller, J.L. (1993). Fair pay for fair play: Estimating pay equity in professional baseball with data envelopment analysis. Acad Manage J, 36(4), 882-894.

[11] Hung, S.W., He, D.S. and Lu, W.M. (2014). Evaluating the dynamic performances of business groups from the carry-over perspective: A case study of Taiwan's semiconductor industry. Omega, 46, 1-10. 
[12] Hung, S.W. and Wang, A.P. (2012). Entrepreneurs with glamour? DEA performance characterization of high-tech and older-established industries. Econ Model, 29(4), 1146-1153.

[13] Jane, W.J., Kong, W.H. and Wang, Y.H. (2010). Individual efficiency and club performance: a panel analysis of professional baseball. Manag Decis Econ, 31(5), 363-372.

[14] Kearney, A.T. (1984). Measuring and improving productivity in physical distribution, Council of Logistics Mana.

[15] Lewis, H.F. and Sexton, T.R. (2004). Data envelopment analysis with reverse inputs and outputs. J Prod Anal, 21(2), 113-132.

[16] Lewis, H.F., Sexton, T.R. and Lock, K.A. (2007). Player salaries, organizational efficiency, and competitiveness in Major League Baseball. J Sports Econ, 8(3), 266-294.

[17] McWilliams, A., Siegel, D. and Van Fleet, D.D. (2005). Scholarly journals as producers of knowledge: Theory and empirical evidence based on data envelopment analysis. Organ Res Methods, 8(2), 185-201.

[18] Mentzer, J. T. and Konrad, B. P. (1991). An efficiency/effectiveness approach to logistics performance analysis. Journal of Business Logistics, 12(1), 33.

[19] Rogers, E.M. (2003). Elements of diffusion. Diffusion of Innovations, 5(1.38).

[20] Rottenberg, S. (1956). The baseball players' labor market. J Polit Econ, 64(3), 242-258.

[21] Scully, G.W. (1994). Managerial efficiency and survivability in professional team sports. Manag Decis Econ, 15(5), 403-411.

[22] Sexton, T.R. and Lewis, H.F. (2003). Two-stage DEA: An application to major league baseball. J Prod Anal, 19(2-3), 227-249.

[23] Smart, D.L. and Wolfe, R.A. (2000). Examining sustainable competitive advantage in intercollegiate athletics: A resource-based view. J Sport Manag, 14(2), 133-153.

[24] Tsai, J.M. and Hung, S.W. (2014). A novel model of technology diffusion: System dynamics perspective for cloud computing. J Eng Tech Manage, 33, $47-62$.

[25] Wasserman, S. and Faust, K. (1994). Social network analysis: methods and applications (Vol. 8).Cambridge university press.

[26] Volz, B. D. (2016). DEA Applications to Major League Baseball: Evaluating Manager and Team Efficiencies. Data Envelopment Analysis, 93-112. 